\title{
Dosagem de marcadores de lesão endotelial em pacientes com doença renal crônica em hemodiálise
}

Primeira submissão em 02/04/09 Última submissão em 19/03/10 Aceito para publicação em 08/04/10 Publicado em 20/06/10

\section{Endothelial lesion markers dosage in chronic renal disease patients undergoing hemodialysis}

Cláudia Maria Pereira Alves'; Maria do Carmo Borges Teixeira²; Maria Cristina De Martino ${ }^{3}$

\section{unitermos Hemodiálise}

Hepatite C

ICAM-1

VEGF

\section{resumo}

Introdução: Pacientes com doença renal crônica (DRC) em diálise têm como principal causa de morte doença cardiovascular (DCV) aterosclerótica, tendo a inflamação e a disfunção endotelial relação direta com a aterosclerose. Além disso, a infecção pelo vírus da hepatite $\mathrm{C}(\mathrm{HCV})$, comum nestes pacientes, seria outro fator de piora do estado inflamatório. Níveis aumentados de marcadores de disfunção endotelial são encontrados em pacientes com DRC e hepatite $C$, e poderiam ser importantes marcadores de aterosclerose nestes indivíduos. Objetivo: Comparar atividade endotelial de pacientes em hemodiálise com e sem hepatite $\mathrm{C}$. Metodologia: Selecionamos 28 pacientes em hemodiálise que foram divididos em dois grupos: 1-HCV(+): 18 pacientes (anti-HCV[+] e PCR[+]) e 2-HCV(-): 10 pacientes (anti-HCV[-]). Antes da primeira diálise da semana foi coletada amostra de sangue para dosagem sérica de molécula de adesão intercelular-1 (ICAM-1), fator de crescimento vascular endotelial (VEGF), aspartato alanina aminotransferase (ALT) e tempo de atividade da protrombina (TAP) dos grupos. Resultados: Os níveis de ICAM-1 foram elevados em $60,71 \%$, sendo maiores no grupo $\mathrm{HCV}(+)$, porém não estatisticamente significativos $(p=0,2024)$. Não houve correlação entre os níveis de ICAM-1 e tempo de diálise ou níveis de ALT em nenhum dos grupos. Já os níveis de VEGF foram normais em 92,85\%; apenas dois pacientes HCV(+) tinham níveis elevados. Também não houve correlação com tempo de diálise ou níveis de ALT em nenhum grupo. Conclusão: Pacientes em hemodiálise possuem elevada lesão endotelial, porém a presença de infecção crônica pelo HCV não se mostrou um fator agravante deste quadro. Este resultado pode ter ocorrido por conta do pequeno número de pacientes, sendo necessárias análises com maior número de indivíduos para conclusões mais definitivas. abstract

Introduction: Chronic renal patients undergoing hemodialysis treatment have cardiovascular atherosclerotic disease as the main cause of death. Inflammation and endothelial dysfunction are directly associated with atherosclerosis. Furthermore, the infection resulting from hepatitis $C$ virus, common among such patients, would be another worsening factor of the inflammatory state. Increased levels of endothelial dysfunction markers are found in chronic renal disease and hepatitis $C$, which could be important markers of atherosclerosis among these subjects. Objective: To compare endothelial activity in patients undergoing hemodialysis with and without hepatitis C. Methodology: We selected 28 patients undergoing hemodialysis and classified them into two groups: 1-HCV(+): 18 patients (anti-HCV[+] and PCR[+]) and 2-HCV(-): 10 patients (anti-HCV[-]). Before the first weekly dialysis, blood samples from both groups were collected for ICAM-1, VEGF, ALT and TAP serum dosage. Results: ICAM-1 levels were high in $60.71 \%$. The highest levels were found in HCV(+) group, though not statistically significant $(\mathrm{p}=0.2024)$. There was no correlation between ICAM-1 levels and the hemodialysis time or ALT levels in any group. On the other hand, VEGF levels were normal in $92.85 \%$. Only two patients $\mathrm{HCV}(+)$ had high levels. There was also no correlation between VEGF levels and the dialysis time or ALT levels. Conclusion: Patients undergoing hemodialysis have high endothelial lesion, nevertheless, the presence of HCV chronic infection did not prove to be an aggravating factor. This result may be due to the small number of patients, hence further analyses with a larger sample are required for definitive conclusions. key words

Hemodialysis

Hepatitis $C$

ICAM-1

VEGF

1. Nefrologista da Universidade Estadual de Ciências da Saúde de Alagoas (UNCISAL); mestra em ciências pela Escola Paulista e Medicina da Universidade Federal de São Paulo (EPM/UNIFESP).

2. Professora-doutora adjunta de Nefrologia da UNCISAL.

3. Bióloga; coordenadora de Qualidade, Validação e Pesquisa da Associação Fundo de Incentivo à Psicofarmacologia (AFIP) Medicina Laboratorial.

Trabalho realizado na UNCISAL e EPM/UNIFESP. 


\section{Introdução}

A doença renal crônica (DRC) é uma síndrome complexa consequente à perda da capacidade excretora renal e reconhecida como um problema de saúde pública mundial(17); a doença cardiovascular (DCV) aterosclerótica prematura é muito comum entre os renais crônicos mantidos em hemodiálise (HD), sendo a principal causa de morte neste grupo ${ }^{(24,27,35)}$ e não podendo ser inteiramente explicada pelos fatores de risco convencionais. A inflamação e a disfunção endotelial são apontadas no início, na progressão e na propagação do processo de aterosclerose, sendo esta mais pronunciada na DRC do que na doença cardíaca isquêmica ${ }^{(27,35)}$. A infecção pelo vírus da hepatite C (HCV) também é outro fator de risco independente de morte para pacientes com DRC em hemodiálise ${ }^{(21,23,33)}$. Esta infecção predispõe, ainda, ao desenvolvimento de alterações imunológicas que podem prejudicar a resposta inflamatória aguda, levar a queda de hipersensibilidade e alteração na função imune tardia ${ }^{(3,31)}$, porém a relação entre hepatite $\mathrm{C}$ e inflamação crônica permanece indeterminada até o momento.

O estado inflamatório crônico nos pacientes com DRC em hemodiálise pode ser atribuído também a: constante ativação de monócitos e neutrófilos circulantes durante a passagem do sangue através do circuito de diálise, transferência de endotoxinas da membrana do capilar de diálise para o sangue durante as sessões, ativação de citocinas pró-inflamatórias e, principalmente, alterações endoteliais ${ }^{(1,2,14,23,25,28)}$. Células endoteliais são ativadas com expressão de moléculas de adesão celular que se ligam aos leucócitos e migram para os tecidos inflamados ${ }^{(19,32)}$. A molécula de adesão intercelular 1 (ICAM-1) cumpre importante papel no recrutamento e na retenção de células pró-inflamatórias. A ativação, a circulação e a migração de leucócitos para sítios inflamatórios dependem desta molécula ${ }^{(18,32)}$. É possível dosar, na circulação, a forma solúvel da ICAM-1. Estes níveis refletem a intensidade da

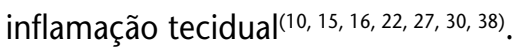

Níveis aumentados foram detectados no soro de pacientes com síndromes coronarianas agudas e pacientes com disfunções renais ${ }^{(27,35)}$. Como a inflamação crônica é uma condição comum nos pacientes em HD, além de um fator independente de mortalidade ${ }^{(23,27,35)}$, os níveis séricos elevados das moléculas de adesão poderiam indicar, pelo menos hipoteticamente, o surgimento de um marcador do processo que contribui para a alta mortalidade em diálise ${ }^{(23,27)}-$ a aterosclerose.
Outro marcador de lesão endotelial que tem sido relacionado com doença aterosclerótica é o fator de crescimento vascular endotelial (VEGF), uma glicoproteína secretada na parede vascular pelo endotélio e por células musculares lisas. É um mitógeno que promove proliferação vascular de células endoteliais e angiogênese alterada em condições patológicas, como aterosclerose, retinopatia diabética e neoplasias ${ }^{(9)}$. O VEGF está aumentado na doença arterial periférica e coronariana e tem sido implicado na progressão da aterosclerose e da lesão vascular desestabilizadora. Evidências recentes sugerem um papel pró-aterosclerótico deste marcador de lesão endotelial por meio da habilidade de acentuar a infiltração inflamatória na placa e também a neovascularização ${ }^{(20)}$. Níveis elevados foram encontrados em lesões arteriais ateromatosas iniciais e avançadas, demonstrando seu envolvimento desde o princípio na progressão da lesão aterosclerótica ${ }^{(13,20)}$.

Além disso, tem sido proposto que a concentração sérica das moléculas de adesão se correlacionam com a disfunção endotelial ${ }^{(14,23,27,35)}$. Seria coerente ponderar também que a presença de infecção crônica pelo vírus $C$ da hepatite nos pacientes renais crônicos em HD poderia estar relacionada com elevados níveis séricos de ICAM-1 e VEGF, exacerbando o estado inflamatório deste pacientes. Por conta disso nos propusemos avaliar se há relação entre a DRC dialítica, a hepatite $\mathrm{C}$ e o estado inflamatório, por meio da avaliação dos marcadores séricos de disfunção endotelial ICAM-1 e VEGF, determinando, assim, o valor desses marcadores na detecção precoce da DCV nesses pacientes.

\section{Objetivo}

O objetivo do nosso estudo foi comparar a atividade endotelial entre pacientes com DRC submetidos à hemodiálise, portadores e não portadores de hepatite $C$, por meio da dosagem dos níveis séricos de ICAM-1 e VEGF.

\section{Materiais e métodos}

Trata-se de um estudo prospectivo transversal em uma amostra de pacientes portadores de DRC terminal, com e sem infecção pelo HCV, submetidos a tratamento regular de hemodiálise em seis centros de diálise na cidade de Maceió-AL. Foram incluídos pacientes com idade > 18 anos; em programa de hemodiálise há mais de 30 dias; com sorologias positivas e negativas para hepatite $\mathrm{C}$, sendo os grupos definidos da seguinte maneira: aqueles com 
anti-HCV reagente e reação em cadeia da polimerase (PCR) positivo - grupo $\mathrm{HCV}(+)$, enquanto os com anti-HCV não reagente - grupo $\mathrm{HCV}(-)$. Foram excluídos pacientes < 18 anos; com disfunção renal aguda; portadores de coinfecção pelo vírus da hepatite B (HBV) e/ou HIV; com diagnóstico de Sjögren e/ou lúpus eritematoso sistêmico (LES); aqueles que estivessem em tratamento com interferon alfa; pacientes em uso de drogas imunossupressoras; com infecção ativa de qualquer natureza no momento da avaliação; que realizaram transplante renal durante a investigação; portadores de neoplasias de qualquer natureza e gestantes. O consentimento informado foi obtido de cada paciente no momento da entrevista.

Dos 569 pacientes com DRC em hemodiálise analisados inicialmente, 61 (10,72\%) tiveram diagnóstico de hepatite $C$ com base na positividade do anti-HCV pelo ensaio imunossorvente ligado à enzima (ELISA), terceira geração - técnica imunoenzimática, empregando micropartículas de terceira geração (Abbott Laboratories, IMX). Nos pacientes que apresentaram sorologia positiva para o HCV foi realizada pesquisa do RNA viral no soro por meio da técnica de PCR método de reação em cadeia da polimerase com transcrição reversa (RT-PCR) quantitativo (Invitrogen Life Technologies, CA, EUA). Um total de 25 pacientes $(40,98 \%)$ apresentava viremia $(\mathrm{PCR}+)$, sendo, então, estes os eleitos inicialmente para o estudo no grupo $\mathrm{HCV}(+)$. Também selecionamos 10 pacientes renais crônicos em HD sem hepatite $C$ para o grupo controle - grupo $\mathrm{HCV}(-)$. Dos 25 pacientes do grupo $\mathrm{HCV}(+)$ foram excluídos dois por serem menores de 18 anos, um paciente se recusou a participar e três faleceram no início da investigação. No decorrer do estudo um paciente realizou transplante renal, não sendo possível concluir a avaliação. Restaram neste grupo, então, 18 pacientes.

Nos dois grupos foi realizada a dosagem dos níveis séricos de ICAM-1, VEGF, aspartato alanina aminotransferase (ALT) e do tempo de atividade de protombina (TAP). As amostras de sangue foram coletadas no centro de diálise, em dia e horário do tratamento hemodialítico regular dos pacientes imediatamente antes do início da diálise e da administração de heparina, na primeira sessão de HD da semana. Foi colhida uma amostra de sangue em tubo sem anticoagulante e outra com anticoagulante ácido etilenodiaminotetracético (EDTA) (para determinação do TAP), por meio de punção de veia periférica. Aproveitamos a própria punção da fístula arteriovenosa, que é o acesso vascular utilizado para hemodiálise, não sendo necessário submeter os pacientes a mais nenhuma punção além das que já se fazem regularmente para seu tratamento.

\section{Técnica de preparo do material para dosagem das moléculas de adesão}

Após a coleta do sangue, o material sem anticoagulante foi deixado em repouso por 30 minutos e, em seguida centrifugado por 10 minutos em rotação de 2.500 RPM e aliquotado em $3 \mathrm{ml}$ de soro divididos em ependorf de $1 \mathrm{ml}$. Congelado, rapidamente, flash freezer em nitrogênio líquido e mantido em freezer a menos $70^{\circ} \mathrm{C}$ para posterior dosagem dos marcadores de lesão endotelial. O material com anticoagulante foi encaminhado após a coleta ao laboratório para a análise.

\section{Análise da molécula de adesão intercelular-1}

A dosagem foi realizada empregando-se o kit sICAM-1 R\&D Systems, Inc. Valores de referência: 115-306 ng/ml; sensibilidade $5 \mathrm{ng} / \mathrm{ml}$; linearidade $5-900 \mathrm{ng} / \mathrm{ml}$; controle: range de bula: 196 a $290 \mathrm{ng} / \mathrm{ml}$; resultado no ensaio: $190 \mathrm{ng} / \mathrm{ml}$; técnica de imunoensaio enzimático quantitativo por sandwich, ELISA.

Princípio do ensaio: em uma placa com poços previamente cobertos com um anticorpo monoclonal específico para a ICAM-1, amostra controle e conjugado, um anti-ICAM-1 recombinante humano marcado com peroxidase (HRP conjugado) foram pipetados para dentro dos poços e qualquer ICAM-1 presente ficou entre o anticorpo imobilizado e a enzima ligada ao anticorpo monoclonal específico para o ICAM-1, por isso dá-se o nome de técnica em sandwich. Seguiu-se com uma lavagem para remover qualquer outra substância e/ou anticorpos reagentes com a enzima. Após a lavagem, foi adicionado substrato (solução tetrametilbenzidina [TMB]) nos poços, desenvolvendo-se uma coloração cuja intensidade foi proporcional à quantidade de ICAM-1 presente. O processo foi interrompido por solução bloqueadora e avaliado espectrofotometricamente por medição e comparação da intensidade da cor desenvolvida nos poços dos pacientes com a cor nos poços controles. Para determinação quantitativa da concentração de ICAM-1, os valores obtidos para cada amostra foram estimados por interpolação em curva construída com padrões conhecidos. Para pacientes e controles, a concentração de ICAM-1 determinada pela curva modelo foi multiplicada pelo fator de diluição $(\times 20)$.

\section{Análise do fator de crescimento endotelial vascular}

A dosagem foi realizada empregando-se o kit: Human VEGF Imumunoassay, R\&D Systems, Inc.: valores de referência: $62-707 \mathrm{pg} / \mathrm{ml}$; sensibilidade: $<5 \mathrm{pg} / \mathrm{ml}$; 
linearidade: $5-2.000 \mathrm{pg} / \mathrm{ml}$. Técnica de imunoensaio enzimático quantitativo por sandwich, ELISA.

Princípio do ensaio: anticorpo monoclonal específico para VEGF é colocado previamente sobre uma placa. Amostra do controle e conjugado (HRP-conjugado) é pipetada para dentro dos poços e qualquer VEGF presente ficará retido entre o anticorpo imobilizado e a enzima ligada ao anticorpo monoclonal específico para o VEGF. Segue-se com uma lavagem para remover qualquer outra substância e/ou anticorpos reagentes com a enzima. Após a lavagem, adicionou-se substrato $T M B$ nos poços desenvolvendo uma coloração cuja intensidade será proporcional à quantidade de VEGF presente. O processo é interrompido por solução bloqueadora (ácido sulfúrico) e avaliado espectrofotometricamente por comparação da intensidade da cor desenvolvida nos poços dos pacientes com a cor nos poços controles. Para determinação quantitativa da concentração de VEGF, os valores obtidos para cada amostra são estimados por interpolação em curva construída com padrões conhecidos.

\section{Avaliação da atividade necroinflamatória e função hepática}

É realizada por meio da dosagem de ALT, para avaliação da ocorrência de lesão hepática e determinação do TAP, para avaliação da função hepática.

\section{Análise estatística}

A análise descritiva das variáveis contínuas foi expressa com os respectivos valores mínimos, máximos, média, desvios padrão e medianas. As variáveis categóricas foram descritas em porcentagem. Para avaliar a existência de associação, a comparação entre as médias em dois grupos foi calculada pelo teste $t$ de Student, e entre três grupos foi utilizada a análise de variância (ANOVA). Quando ocorreu significância estatística, realizamos o teste de post-hoc de Boferroni. O grau de correlação entre as variáveis de escala métrica foi obtido pelo coeficiente de correlação de Pearson. As variações foram consideradas significativas com valores menores ou iguais a 0,05 ou $5 \%(p \leq 0,05)$, assinalandose com um asterisco estes valores. As correlações foram consideradas existentes com $r=1$.

\section{Resultados}

\section{Características gerais da amostra}

Dos pacientes selecionados, $68 \%$ eram do sexo masculino; a idade variou entre 20 e $69(45,39 \pm 14,11)$ anos.
O tempo de tratamento dialítico variou de seis meses a 22 anos, com média de 7,45 $\pm 6,35$ anos; o tempo em diálise foi significativamente maior nos portadores de hepatite C. A maioria dos pacientes (39\%) teve como etiologia da DRC a hipertensão arterial sistêmica (HAS), seguido de glomerulonefrite crônica (32\%) diabetes mellitus (DM) (14\%), pielonefrite crônica (6,8\%), outras causas $(6,8 \%)$ e etiologia não definida $(6,8 \%)$. Dos pacientes com HCV(+), 14 adquiriram a infecção após o início da hemodiálise $(77,77 \%)$ - transmissão nosocomial. A transfusão sanguínea foi responsável pelo contágio do vírus $C$ em apenas dois pacientes, não havendo significância entre o número de transfusões recebidas no grupo $\mathrm{HCV}(+)$ e no $\mathrm{HCV}(-)$, (29 vs. 24 transfusões, respectivamente, $p=0,0861)$. Nos outros dois pacientes com hepatite a fonte do contágio não pôde ser identificada. Apenas um paciente havia recebido tratamento para o vírus $C$ com interferon alfa no passado, antes do início do tratamento dialítico (Tabela $\mathbf{1}$ ).

\section{Atividade endotelial}

A dosagem sérica de ICAM-1 se mostrou elevada em $60,71 \%$ dos pacientes; o grupo $\mathrm{HCV}(+)$ mostrou níveis mais elevados que o grupo HCV(-), porém não houve diferença estatisticamente significativa entre eles $(p=0,2024)$. Não houve correlação entre os níveis de ICAM-1 com o tempo de tratamento dialítico e os níveis de ALT em nenhum dos grupos $(r=0)$.

Quando analisamos os níveis séricos de VEGF, estes se mostraram normais em $92,85 \%$ dos pacientes. Apenas dois indivíduos com hepatite $C$ apresentaram níveis de VEGF acima do normal. Também não houve correlação entre os níveis de VEGF com o tempo de tratamento dialítico e os níveis de ALT em nenhum dos grupos $(r=0)$ (Tabela 2; Figuras 1 e 2).

\section{Avaliação da atividade necroinflamatória e da função hepática}

Nos pacientes em geral os níveis de ALT foram normais, entretanto, apesar disso, foram significativamente mais elevados nos pacientes com vírus $C(p=0,0008)$.

O valor do TAP foi menor no grupo HCV $(p=0,0187)$; todavia ainda encontrando-se nos limites da normalidade, mostrando, assim, que a função hepática se mantinha preservada nesta amostra (Tabela 3). 
Tabela 1 Características gerais dos pacientes

\begin{tabular}{|c|c|c|c|c|}
\hline & $\begin{array}{c}\text { Total } \\
n=28(\%)\end{array}$ & $\begin{array}{c}\mathrm{HCV}(+) \\
n=18(\%)\end{array}$ & $\begin{array}{c}\mathrm{HCV}(-) \\
n=10(\%)\end{array}$ & $\begin{array}{c}p \\
\operatorname{HCV}(+) \vee S_{n}, H C V(-)\end{array}$ \\
\hline Sexo masculino & $19(68)$ & $14(68)$ & $5(50)$ & - \\
\hline Sexo feminino & $9(32)$ & $4(32)$ & $5(50)$ & - \\
\hline Idade & $45,39+14,11$ & $49,67+9,5$ & $34,22+18,17$ & NS \\
\hline Tempo de diálise & $7,45+6,35$ & $9,57+7,07$ & $3,64+1,2$ & $0,0149 *$ \\
\hline \multicolumn{5}{|l|}{ Etiologia da DRC } \\
\hline Hipertensão arterial & $11(39)$ & $8(44,5)$ & $3(30)$ & NS \\
\hline $\begin{array}{l}\text { Glomerulonefrite } \\
\text { crônica }\end{array}$ & $9(32)$ & $3(16,6)$ & $6(60)$ & NS \\
\hline Diabetes mellitus & 04 (14) & $3(16,6)$ & $1(10)$ & NS \\
\hline Pielonefrite crônica & $2(6,8)$ & $2(11)$ & - & NS \\
\hline Outras causas & $02(6,8)$ & $2(11)$ & - & NS \\
\hline Desconhecida & $02(6,8)$ & $2(11)$ & - & NS \\
\hline Transfusões sanguíneas & 53 & 29 & 24 & NS \\
\hline \multicolumn{5}{|c|}{ Forma de contágio pelo HCV } \\
\hline Transfusão & $02(11,11)$ & - & - & - \\
\hline Pós-início HD & $14(77,77)$ & - & - & - \\
\hline Desconhecida & $02(11,11)$ & - & - & - \\
\hline $\begin{array}{l}\text { Tratamento prévio com } \\
\text { interferon alfa }\end{array}$ & $1(5,55)$ & - & - & - \\
\hline
\end{tabular}

Nivel descritivo de valores expressos em média \pm 1 desvio padrão. *HCV(+) $>$ grupo HCV(-). HCV: vírus da hepatite C; DRC: doença renal crônica; HD: hemodiálise; NS: não significativo.

\section{Tabela 2 Atividade endotelial}

\begin{tabular}{lcccc}
\hline & Total & HCV $(+)$ & HCV(-) & P \\
ICAM-1 ng/ml & $402+182,1$ & $435,1+188,6$ & $342+161,8$ & HCV $(+)$ VS. HCV $(-)$ \\
VEGF pg/ml & $295,4+237,9$ & $348,9+268,5$ & $199+132,8$ & NS \\
\hline
\end{tabular}

Nivel descritivo de valores expressos em média \pm 1 desvio padrão.

HCV: vírus da hepatite C; NS: não significativo; ICAM-1: molécula de adesão intercelular-1; VEGF: fator de crescimento vascular endotelial.

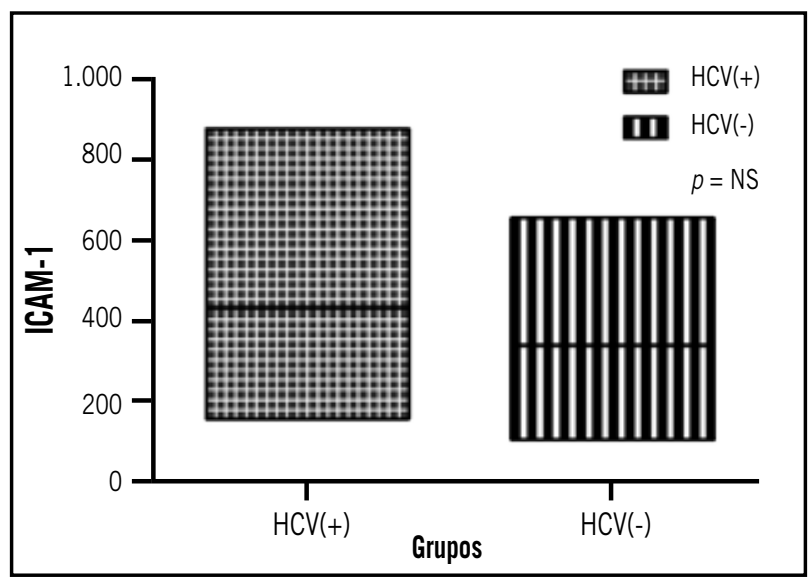

Figura 1 - Níveis séricos de ICAM-1

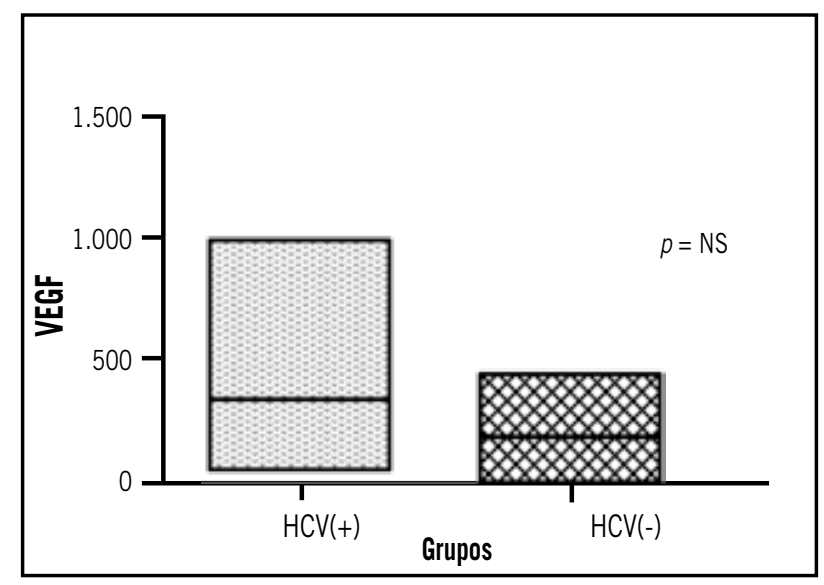

Figura 2 - Niveis séricos de VEGF 
Tabela 3 Avaliação da atividade necroinflamatória e da função hepática

\section{Todos os pacientes \\ $\mathrm{HCV}(+)$ \\ HCV(-)}

$35,23+24,42$

$45,89+23,49$

$92,34+7,67$

$89,86+7,81$
$16,05+10,57$

$96,80+5,19$ p

$\mathrm{HCV}(+)$ VS. HCV(-)

TAP $(\%)$

$0,0008^{*}$

${ }^{*} \mathrm{HCV}(+)>\mathrm{HCV}(-) ;{ }^{* *} \mathrm{HCV}(-)>\mathrm{HCV}(+)$.

HCV: vírus da hepatite C; ALT: aspartato alanina aminotransferase; TAP: atividade da protrombina.

\section{Discussão}

Atualmente as doenças crônicas são as principais causas de morte em todo o mundo. No relatório de 2005 da Organização Mundial da Saúde (OMS) foram estimadas 35 milhões de mortes atribuídas às doenças crônicas. As DCVs continuam sendo a principal causa, mas já é reconhecido que a DRC, além de ser um fator de risco para DCV, também multiplica a chance de um desfecho fatal nesses $\operatorname{casos}^{(17)}$. A DCV aterosclerótica é a principal causa de morte entre os pacientes com DRC terminal mantidos em $H D^{(24,27,35)}$. Também já está estabelecido que a disfunção endotelial faz parte do processo inicial da aterosclerose. A inflamação e a disfunção endotelial são mais pronunciadas na disfunção renal avançada, caracterizando um estado inflamatório crônico nestes indivíduos ${ }^{(27,35)}$. A concentração sérica de moléculas de adesão solúveis é elevada ${ }^{(14)}$, sendo estas importantes marcadores de disfunção endotelial nesta condição clínica. Outro fator que poderia contribuir para um pior prognóstico nestes pacientes é a infecção crônica pelo $\mathrm{HCV}^{(21,23,33) ;}$ a presença desta infecção pode piorar ainda mais o quadro inflamatório já existente.

O predomínio do sexo masculino em nossa amostra, bem como a hipertensão como a principal que levou à perda da função renal, é compatível com os estudos epidemiológicos anteriormente realizados no Brasi ${ }^{(4,26)}$. Pacientes que iniciaram HD antes da década de 1990 tiveram mais risco de contrair o HCV devido à falta de exames diagnósticos e à ausência de cuidados preventivos até aquela década; portanto nada mais natural que este grupo apresentar um tempo em diálise maior em relação ao grupo sem hepatite.

Chamou-nos muito a atenção o fato de que aproximadamente $78 \%$ dos pacientes portadores de hepatite $\mathrm{C}$ tenha adquirido a doença após o início do tratamento dialítico, demonstrando com isso que a transmissão nosocomial continua a ser a via mais importante de disseminação do HCV entre estes pacientes e comprovando que os cuidados de prevenção estão aquém do necessário e esperado, o que sem dúvida é muito preocupante e precisa ser modificado.
A determinação dos níveis séricos das aminotransferases, ALT em particular, por ser mais sensível, é considerada um bom teste para rastreamento de doença hepática em pacientes fora de tratamento dialítico, pois dá condições de avaliar a atividade necroinflamatória hepática causada pela ação do vírus nos hepatócitos. Contudo sua determinação tem sido um parâmetro de utilidade discutível no diagnóstico de lesão hepática nos pacientes com infecção pelo vírus $C$ submetidos a $H D$, porque apenas $10 \%-15 \%$ destes pacientes apresentam níveis elevados de transaminases ${ }^{(6)}$. Os níveis séricos de ALT costumam estar dentro, ou até abaixo, dos limites normais de referência nos pacientes com DRC que fazem hemodiálise em comparação com aqueles em fase pré-dialítica ${ }^{(11,36)}$. Em nossa amostra não foi diferente: os níveis de ALT encontravam-se normais. A causa dessa redução da atividade das aminotransferases nos renais crônicos em HD não está completamente esclarecida. As prováveis causas seriam: a) o sequestro do genoma viral pelo capilar da diálise, levando a uma baixa viremia; b) deficiência de piridoxina - cofator na síntese das aminotransferases ${ }^{(11)}$; c) interferência das substâncias urêmicas do soro destes pacientes na dosagem laboratorial por método ultravioleta ${ }^{(36)}$; d) estimulação, pela HD, da produção do hormônio de crescimento hepático, potente estimulador de mitose hepática que promove a regeneração dos hepatócitos ${ }^{(11,26)}$. Podemos pensar que nos pacientes submetidos a tratamento hemodialítico talvez se torne indispensável considerar diferentes limites de referência para as aminotransferases, reduzindo-se o ponto de corte. Como vimos que a doença hepática pelo vírus $\mathrm{C}$ é menos pronunciada nos pacientes em hemodiálise, a função hepática preservada encontrada em nossa amostra corrobora os achados prévios ${ }^{(5-8,811,12,26,36,37)}$. Tivemos pacientes com mais de 20 anos de infecção viral que não evidenciavam alteração na reserva hepática.

Há muito se tem demonstrado que vários fatores contribuem para que o paciente com DRC em tratamento dialítico apresente um estado inflamatório crônico. A hemodiálise provoca ativação dos monócitos e neutrófilos circulantes, ativação de complemento, transferência de endotoxinas 
para o sangue, ativação de citocinas pró-inflamatórias e, principalmente, alterações endoteliais. Todas estas alterações foram evidenciadas por diversos estudos ao longo dos anos ${ }^{(1,2,14,23,25,28)}$. Níveis séricos aumentados de marcadores de lesão endotelial são encontrados na aterosclerose $\mathrm{e}^{(14,23,27)}$ e existe uma disfunção endotelial mais pronunciada na DRC que na doença cardíaca isquêmica pura ${ }^{(27,35)}$. Isso faz da DCV aterosclerótica prematura uma ocorrência muito comum entre os indivíduos em $\mathrm{HD}^{(24,27,35)}$.

Níveis séricos elevados de ICAM-1 foram detectados na maioria de nossos pacientes, mas não tiveram correlação com tempo em diálise ou com os níveis de ALT e TAP em nenhum dos grupos, mostrando que a infecção viral não foi um agravante para o estado inflamatório crônico proveniente da DRC. Apesar da ocorrência elevada de aterosclerose nos pacientes renais crônicos e de evidências de disfunção endotelial nestes pacientes, ainda não tínhamos estudos que tivessem avaliado os níveis de VEGF, implicado na progressão da aterosclerose nesta população. Em nossa amostra, ao contrário do ICAM-1, os níveis de VEGF foram normais em praticamente todos os pacientes e, da mesma forma que ocorreu com o ICAM-1, também não encontramos correlação entre os níveis de VEGF e o tempo de tratamento dialítico, níveis de ALT e TAP. Neste caso, nem a hemodiálise nem o vírus $C$ promoveram a ativação desta molécula. Assim, o VEGF não se mostrou bom marcador de disfunção endotelial na DRC.

\section{Conclusão}

O estudo demonstrou que pacientes renais crônicos que fazem HD possuem elevada lesão endotelial, porém a presença de infecção crônica pelo HCV não se mostrou um fator agravante deste quadro. Apenas o ICAM-1 se mostrou útil para a avaliação da atividade endotelial nestes pacientes. É possível que estes resultados advenham da amostra limitada de pacientes, sendo necessárias análises posteriores com um número maior de indivíduos para conclusões mais definitivas e podendo, desta forma, estabelecer o papel patogênico da atividade endotelial em pacientes com DRC em hemodiálise portadores infecção crônica pelo HCV e a importância da dosagem sérica dos marcadores de lesão endotelial para este grupo de pacientes.

\section{Referências}

1. BOLTON, C. H. et al. Endothelial dysfunction in chronic renal failure: roles of lipoprotein oxidation and proinflammatory cytokines. Nephrol Dial Transplant, n. 16, p. 1189-97, 2001.

2. BOMOMINI, M. et al. Serum levels of soluble adhesion molecules in chronic renal failure and dialysis patients. Nephron, n. 79, p. 399-407, 1998.

3. CAVANESE, C. et al. Extrahepatic immunological manifestations of hepatitis $C$ virus in dialysis patients. J Nephrol, n. 13, p. 352-9, 2000.

4. CENSO da Sociedade Brasileira de Nefrologia - JBN, 2007. Disponível em: <http://www.sbn.org.br>. Acesso em: 09 abr. 2008.

5. ESPINOSA, M. et al. High ALT levels predict viremia in anti-HCV-positive HD patients if a modified normal range of ALT is applied. Clin Nephrol, v. 54, n. 2, p. 151-6, 2000.

6. FABRIZI, F. et al. Virological characteristics of hepatitis $C$ virus infection in chronic hemodialysis patients: a cross-sectional study. Clin Nephrol, v. 44, n. 1, p. 49-55, 1995.

7. FABRIZI, F. et al. Influence of hepatitis C virus (HCV) viraemia upon serum aminotransferase activity in chronic dialysis patients. Nephrol Dial Transplant, n. 12 p. 1394-8, 1997.

8. FABRIZI, F. et al. Biological dynamics of viral load in hemodialysis patients with hepatitis $\mathrm{C}$ virus. Am J Kidney Dis, n. 35, p. 122-9, 2000.
9. FERRARA, N.; DAVIS-SMYTH, T. The biology of vascular endothelial growth factor. Endocr Rev, v. 18, n. 1 p. 4-25, 1997.

10. GEARING A, J. H.; NEWMAN, W. Circulating adhesion molecules in disease. Immunol Today, v. 14, n. 10, p. 506-12, 1993.

11. GOUVEIA, E. C. et al. Identificação de ponto de corte no nível sérico da alanina aminotransferase para rastreamento da hepatite $\mathrm{C}$ em pacientes com insuficiência renal crônica em hemodiálise. Rev Soc Bras Med Trop, n. 37, p. 18-21, 2004.

12. GUH, J. Y. et al. Impact of decreased serum transaminase level on the evoluation of viral hepatitis in hemodialysis patients. Nephron, n. 69, p. 459-65, 1995.

13. INOUE, M.et al. Vascular endothelial growth factor (VEGF) expression in human coronary atherosclerotic lesions. Circulation, n. 98 p. 2108-16, 1998.

14. JACOBSON, S. H. et al. Correlation between soluble markers of endothelial dysfunction in patients with renal failure. Am J Nephrol, n. 22, p. 42-47, 2002.

15. JANDER, S.; HEIDENREICH, F.; STOLL, G. Serum and CSF levels of soluble intercellular adhesion molecule-1 (ICAM-1) in inflammatory neurologic diseases. Neurology, v. 43, n. 9 p. 1809-13, 1993.

16. LABARRERE, C. A.; NELSON, D. R.; FAULK, W. P. Endothelial activation and development of coronary artery disease in transplanted human hearts. JAMA, v. 278, n. 14 , p. 1169-75, 1997. 
17. LEVEY, A. S. et al. Doença renal crônica como um problema global de saúde pública: enfoques e iniciativas: uma declaração de posição da Kidney Disease: Improving Global Outcomes (KDIGO). Kidney Int (Edição portuguesa), n. 3, p. 232-44, 2007.

18. MCMURRAY, R. W. Adhesion molecules in autoimmune disease. Semin Arthritis Rheum, v. 25, n. 4, p. 215-33, 1996.

19. MARIKOVSKY, M. et al. Cu/Zn superoxido dismutase plays important role in immune response. J Immunol, v. 170, n. 6, p. 2993-3001, 2003.

20. MORSI, W. G. et al. HO-1 and VGEF gene expression in human arteries with advanced atherosclerosis. Clinical Biochemistry, n. 39, p. 1057-62, 2006.

21. NAKAYAMA, E. et al. Prognosis of anti-hepatitis $C$ virus antibody-positive patients on regular hemodialysis therapy. J Am Soc Nephrol, n. 11, p. 1896-902, 2000.

22. NORDOY, I. et al. Abnormal levels of circulating adhesion molecules in HIV-1 infection with characteristic alterations in opportunist infections. Clin Immunol Immunopathol, v. 81, n. 1, p. 16-21, 1996.

23. PENG, Y. S. et al. Influence of hepatitis $C$ virus infection on soluble cellular adhesion molecules in hemodialysis patients. Blood Purif, n. 23, p. 106-12, 2005.

24. PINHEIRO, M. E.; ALVES, C. M. P. Hipertensão arterial na diálise e no transplante renal. JBN, v. 25, n. 3, p. $142-8,2003$.

25. RABB, H. et al. Alterations in soluble intercellular adhesion molecule-1 and vascular cell adhesion molecule- 1 in hemodialysis patients. Am J Kidney Dis, v. 27, n. 2, p. 239-43, 1996.

26. RAMPINO, T. Hemodialysis prevents liver disease caused by hepatitis $\mathrm{C}$ virus: role of hepatocyte growth factor. Kidney Int, n. 56, p. 2286-91, 1999.

27. ROMÃO JUNIOR, J. E. et al. Censo SBN 2002: informações epidemiológicas das unidades de diálise do Brasil. JBN, v. 25 , n. 4 p. $187-98,2003$.

28. RYSZ, J. et al. Blood serum levels of IL-2, IL-6, IL-8, TNF-alpha and IL-1beta in patients on maintenance hemodialysis. Cell Mol Immunol, v. 3, n. 2, p. 151-4, 2006-A.
29. RYSZ, J. et al. Increased levels of soluble TNF- $\alpha$ receptors and cellular adhesion molecules in patients undergoing bioincompatible hemodialysis. Am J Nephrol, n. 26, p. 437-44, 2006-B

30. SFIKAKIS, P. P. et al. Increased levels of intercellular adhesion molecule-1 in the serum of patients with systemic lupus erythematosus. Clin Exp Rheumatol, v. 12, n. 1, p. 5-9, 1994.

31. SHIJUBO, N. et al. Soluble intercellular adhesion molecule-1 (ICAM-1) in sera and bronchoalveolar lavage fluid of patients with idiopathic pulmonary fibrosis and pulmonary sarcoidosis. Clin Exp Immunol, v. 95 , n. 1, p. 156-61, 1994

32. SIAGRIS, D. etal. Viraemia, cryoglobulins and autoantibodies in haemodialysis patients infected with hepatitis $C$ virus. Eur J Gastroenterol Hepatol, n. 15, p. 133-7, 2003.

33. SINGER, K. H. et al. Epidermal keratinocytes express the adhesion molecule intercellular adhesion molecule-1 in inflammatory dermatoses. J invest Dermatol, n. 92, p. 746-50, 1989

34. STEHMAN-BREEN, C.O. et al. Risk of death among chronic dialysis patients infected with hepatitis $\mathrm{C}$ virus. $\mathrm{Am} \mathrm{J}$ Kidney Dis, n. 32, p. 629-34, 1998.

35. SULIMAN, M. E. et al. Hyperhomocysteinemia in relation to plasma free amino acids, biomarkers of inflammation and mortality in patients with chronic kidney disease starting dialysis therapy. Am J Kidney Dis, v. 44, n. 3, p. $455-65,2004$

36. SULIMAN, M. E. et al. Soluble adhesion molecules in endstage renal disease: a predictor of outcome. Nephrol Dial Transplant, n. 21, p. 1603-10, 2006.

37. VAZIRI, N. D.; BARTON, C. H. Serum enzyme levels. In: DAUGIRDAS, J. T.; BLAKE, P. G.; ING, T. S. Handbook of dialysis. 3. ed. Philadelphia: Lippincott Williams \& Wilkins, 2001. cap. 24, p. 448-9.

38. YASUDA, K. et al. Hypoaminotransferase in patients undergoing long-term hemodialysis: clinical and biochemical appraisal. Gastroenterology, n. 109, p. 1295-300, 1995.

39. ZOHRENS, G. et al. Intercellular adhesion molecule-1 concentration in sera of patients with acute and chronic liver disease: relationship to disease activity and cirrhosis. Hepatology, v. 18 n. 4, p. 798-802, 1993. 